\title{
Application of Mathematical Methods and Models in Product - Service Manufacturing Processes in Scientific Innovative Technoparks
}

\author{
Alovsat Garaja Aliyev ${ }^{a^{*}}$, Roza Ordukhan Shahverdiyeva ${ }^{\mathrm{b}}$ \\ ${ }^{a, b}$ Institute of Information Technology of Azerbaijan National Academy of Sciences AZ1141, Azerbaijan \\ Republic, Baku, B.Vahabzade str., 9A
}

Received: 01 March 2018; Accepted: 17 April 2018; Published: 08 July 2018

\begin{abstract}
The article focuses on the application of mathematical methods and models in product - service manufacturing processes in scientific innovative technoparks. The necessity of applying economic-mathematical models and methods in the activity of innovative structures is substantiated. A system of indicators and criteria for assessing the performance and effective management of technoparks has been developed. Based on this system, an information model of the technopark was proposed. A mathematical model of the general management of technoparks is proposed. An econometric model for the innovative product-service manufacturing has been developed. The technique of comparative evaluation of innovative technology parks based on a system of composite indicators and a composite index is proposed. As a result of the experimental implementation of these methods and models, the activity of technoparks.
\end{abstract}

Index Terms: Information economy, innovative economy, technopark, science and technology park, composite indicator system, economic-mathematical model, econometric model, statistic assessment.

(C) 2018 Published by MECS Publisher. Selection and/or peer review under responsibility of the Research Association of Modern Education and Computer Science

\section{Introduction}

At present, the global economy is being developed with the application of new technologies and innovations. Therefore formation and application of scientific and technological innovation policy in the development of the economy in leading countries is considered as one of the main issues. In order to provide sustainability of economic policy and reforms that are being implemented new strategies of economic development are being

* Corresponding author.

E-mail address: alovsat_qaraca@mail.ru, shahverdiyevar@gmail.com 
prepared. In this direction "The Strategic Roadmap for National Economy and the main sectors of economy" was prepared also in Azerbaijan by the end of 2016 [1]. 12 strategic roadmaps approved for national economy and 11 sectors of economy in general are prepared. These roadmaps are increasing the competitiveness, inclusiveness and social welfare of the economy.

Strategic roadmaps include strategy of economic development and action plan for 2016-2020 years, longterm vision for the period up to 2025 and target vision for the post-2025 period. Targeted vision of the SRM (strategic roadmap) for the post-2025 period will provide wide opportunities, expansion of access to quality education, the basis of transition to efficiency and innovation-based economy. The competitive labor force being the main driven force of the economy, regulation of labor market, application of high technologies, including smart machines and systems is the transition of economy from the efficiency-based model to the innovation-based model.

The impact of innovative technologies on the development of new emerging economic fields, automated knowledge creation process, "internet control", remote control technologies, artificial intelligence and robotization, adaptation of management to the requirements of advanced technologies (bio, nano, information, communication, industry, finance, etc.) will be implemented.

On the national economy perspective within the framework of SRM to ensure macroeconomic stability on the basis of effective management, to improve the structure of the economy, to increase employment, to provide balanced regional development, improve the business environment and strengthen the participation of the private sector is planned. The main objective of SRM on development of telecommunication and information technologies, which is one of the 11 sectors of SRM, is the effective functioning of the public sector in the country, improving the level of socio-economic life of the population, development and improvement of ICT infrastructure for health, education, finance, and digitization of the economy in general, increasing the potential of ICT industry of the country.

In the creation of innovation-oriented and knowledge-based economics, 1) the acquisition of high quality and competitive information technology products for international and local markets, 2) creation of clusters and high-technology parks stimulating the development of startups and innovation enterprises are the main goals. High-technology park, scientific and technological innovation technoparks are the main leading force for transition to digital or innovative economy.

"Azerbaijan 2020: Vision to the future" Development Concept [2], also National Strategy of the development of Information Society [3], the issues of development of new management mechanisms, establishment of innovation centers, technological complexes, technoparks, business incubators and organization of their activity to strengthen interaction between science education and industrial sectors are formulated. In addition, in The Science Law [4] the research of problems of formation of the knowledge-based intellectual society and the economy, creation and development of scientific innovation subjects, science, education and entrepreneurship centers, funds, innovation information banks is one of the main goals set before the state and society.

The continuous development and competitiveness of the innovative economy in Azerbaijan, expanding innovation and high technology areas based on modern scientific and technological achievements, carrying out scientific researches and creating modern complexes for the development of new technologies is of great importance.

In order to increase government support to creation of modern complexes, Sumgait industrial and chemical technology park for the formation of high export potential, innovative products or services, "High technologies park" in the Pirallahi, eco-industrial park in Balakhany, the Science and Technology Park, Azerbaijan National Academy of Sciences (ANAS) and the High Technology Park functioning within it, agro and other high-tech parks were established in the regions. All of these make the increase of effectiveness by application of mathematical procedures and methods necessary in innovative production processes in technoparks that are the key element of the innovation infrastructure in the information society. 


\section{Methodological bases of Application of Economic-Mathematical Models and Methods in the Functioning of Technoparks}

İncreasing of the efficiency and innovativeness of technology parks consists of development directions such as 1) increasing of the level of management, 2) using innovative technologies, modern software and ICT, 3) taking into account the prospects for the development of innovative products, 4) applying intellectual systems, 5) modernization of the technopark, development and management of the database, 6) development of mobile management structure, 7) increasing the role of the human factor in improving operating efficiency, 8) taking into account innovation services oriented to customer needs, 9) using of technological opportunities such as modeling, stimulation and prediction etc. Mathematical modeling tools are widely used to increase the production and management operating efficiency of technology parks. Different economic and mathematical models and methods (EMMM) are used in technology parks. The phases of the development of the economic and mathematical model in technopark can be described as in Figure 1 [5].

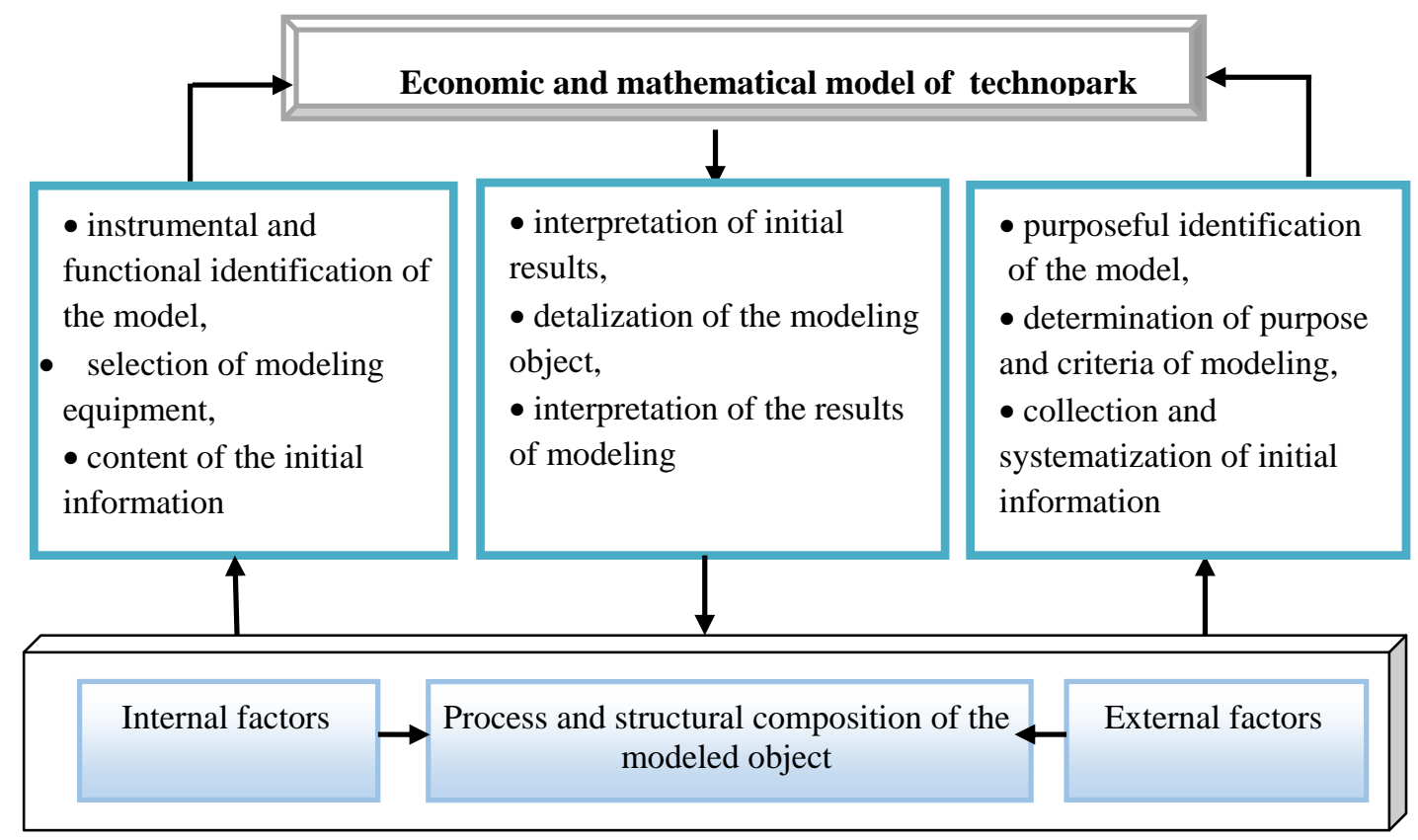

Fig.1. Development Stages of the Economic and Mathematical Model of Technopark

Economic-mathematical modeling process in technoparks consists of components such as 1) object of research; 2) subject (researcher); 3) model, i.e. means expressing relationship between the subject and the perceived object. Models have physical, graphic, and mathematical types. The mathematical model in technoparks is a mathematical description of the processes going on in the object of research. This description consists of equations, tables, limiting conditions, graphs etc. the variables in mathematical model may consist of 1) measurable and manageable variables and 2) variables of random character.

The use of mathematical models and methods in the activity of technoparks is to describe the most important relationships of economic variables and objects in a mathematical way. Mathematical writing (mathematical models) of economic processes or objects is called economic-mathematical modeling. The process of economic-mathematical modeling is based on the economic issue. A mathematical model is built for this issue. 
At the next stage, either the algorithm is being processed, or the originally created algorithm is used for the analysis of this model. If the model and algorithm are not sufficiently complex, then an analytical research of the model may also be possible.

There are 1) theoretical-analytical, 2) applied economic-mathematical models by the purpose of appointment. Technoparks have a number of requirements such as 1) models being sufficiently adequate to the learned economics, 2) models having enough simple mathematical apparatus etc. for building economic-mathematical models (EMM).

In technoparks, EMM is basically grouped according to the following classification [6-8]: 1) structural, 2) non-structural, 3) hybrid models. The models reflecting the connection between the structure of economy and its elements are structural models. In general, it consists of a nonlinear equations system. It provides good results in medium and long-term prediction. The low level of predictive accuracy in this type of models is considered to be one of its weaknesses.

Although non-structural models have high accuracy in the short term, it often doesn't match in medium and long term predictions. It's difficult to take the change of macroeconomic indicators into account in this model. Hybrid models in technoparks are built during joint use of structural and non-structural approaches. The spectrum of hybrid models is very wide. Hybrid models are a combination of two submodels. Here the structural part is used in medium and long-term, and non-structural part is used for short-term prediction.

In technoparks EMMM can also be classified as follows [9]: 1) by the degree of aggregation of objects; 2) by the time factor; 3) by the application areas; 4) by the form of mathematical dependencies; 5) by the type of mathematical tools (apparatus) etc. By application areas and types EMMM can be linear and nonlinear programming, optimization methods, correlation-regression equations, probability theory, mathematical statistics, games theory, network and graph theory, inter-field balance model, econometric model, mass service theory, imitation model etc. In addition, EMM can be classified as: 1) information models, 2) verbal models, 3) character models, 4) computer models by their method of presentation.

One of the main structural types of EMMM in technoparks is econometric model. Correlation and regression analysis among economic indicators is the basis of econometric science. Econometrics - learns the quantity and quality of economic occasions and processes through mathematical, statistical methods and models. One of the main directions of modern economic analysis, Econometrics studies the empirical methods of determining the objective laws in economic processes. Econometrics is a science located in the common range of economy, mathematics and statistics and it has specific distinctive features. The interaction of these sciences can be given as in Figure 2. Econometric models are applied in micro and macro level of the economy. Their construction and adequacy testing are directly related to correlation and regression analysis of mathematical statistics. The content of correlation is to learn interdependence, interaction. The main problem of correlation analysis is revealing the connection between random variables and the evaluation of the density of its connection. The most commonly used method of correlation is regression analysis. The main problem of regression analysis is to determine the form of dependency between variables. Regression analysis is a method of statistical analysis of the effect of one or more independent variables on other dependent variables.

Econometric modeling has the following main stages [5, 6]: 1) stage of formulation of the problem, 2) initial (priori) stage, 3) modeling and parameterization stage, 4) information stage, 5) model identification stage, 6) model verification stage. Econometric models for analysis and prediction: 1) an equilibrium regression model, 2) models consisting of equations given at the same time, 3) models of time dependent rows etc.

Many application software packages are used in the construction of econometric models in technoparks. Such software packages include Eviews, Spss, Stats, Statistica, Limdep, Shazam, Micro Tsp, Minitab, Sas, Matlab, Maple, Excel, Prognosis, Gretl etc. The Econometric Views (EViews) program, one of these software packages has purposes of use such as 1)macroeconomic prediction, 2)analysis of scientific information, 3)modeling of economic processes, 4)analysis of financial issues, 5) prediction of market conditions etc. 


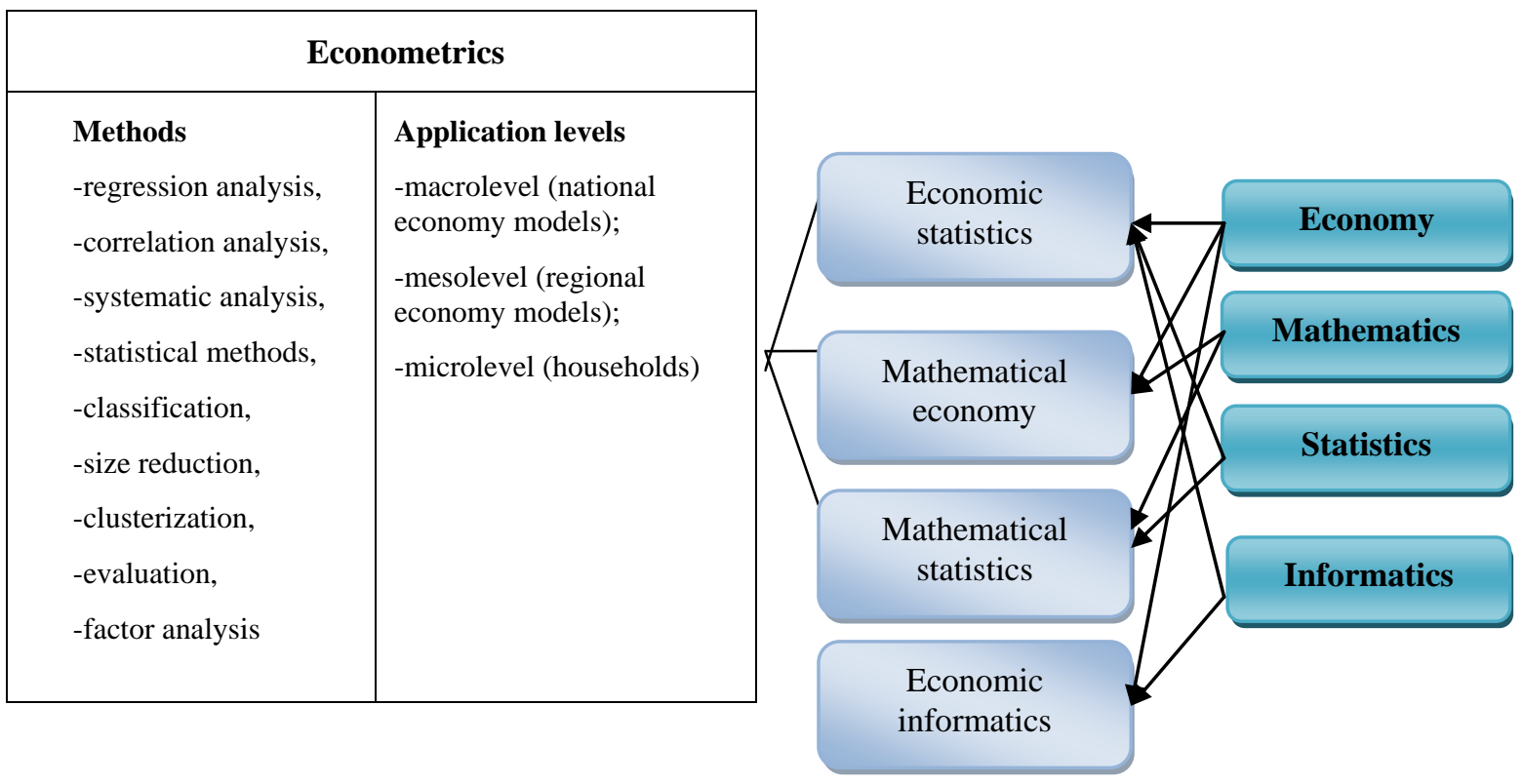

Fig.2. Interaction of Econometrics with Basic Sciences

\section{Establishment of General Mathematical Model of Innovative Products or Services in Technoparks}

The process of establishing a complex model of management of effective activity of technoparks makes using of multi-criterial optimization necessary. Known methods are used in solving structured issues where functional dependence of parameters of technoparks is known. In situations where information about functional dependence is insufficient, the modeling is defined as modeling in completely or partially uncertain circumstances. Elimination of uncertainty in such matters in bad or difficult structured ways can be in two directions: the first direction is related to the use of subjective evaluation and preference principle of the decision-maker when evaluating possible variants of solution.

The second direction which is defined by qualitative and quantitative descriptions of an object or a process is characterized by the use of mathematical methods of information conversion. Therefore it's advisable to fill out uncertain data by using the methods of regression analysis and form the issue of decision-making as a mathematical programming vector problem. There are methods and algorithms based on the normalization of criteria for resolving such issues.They allow resolving the issue with equal value criteria and with the given priority of one criterion over the rest ones.

Regression analysis, methods of solution of the given problems, optimal evaluation methodology of experimental data together is a new information technology model of decision-making under uncertainty conditions. The general picture of that issue can be given as follows [10,11]:

The activity of any technopark depends on the parameters each of which is set at certain limits.

$$
X=\left(x_{1} x_{2} \mathrm{~L} \quad x_{N}\right), X=\left\{x_{i}, i=\overline{1, N}\right\}, x_{i}^{\min } \leq x_{i} \leq x_{i}^{\max }, i=\overline{1, N}
$$

The result of its work can be described with a set of criteria that are functionally dependent on them 


$$
F(X)=\left(f_{1}(X), f_{2}(X), \mathrm{L} f_{k}(X)\right)
$$

The mathematical model of the technopark that solves the problem of choosing the optimal decision entirely can be described as follows:

$$
\begin{aligned}
& F(X) \rightarrow \min , \\
& G(X) \leq 0, \\
& X^{\min } \leq X \leq X^{\max },
\end{aligned}
$$

where $G(X)=\left(g_{1}(X), g_{2}(X), \mathrm{K} g_{m}(X)\right)$ is a vector-function of restrictions imposed on the activity of the technopark. They are identified by technological, economic, and similar processes going on in the technopark and can be described with functional constraints:

$$
f_{k}^{\min } \leq f_{k}(X) \leq f_{k}^{\max }, k=\overline{1, K}
$$

It is considered that $f_{k}(X), k=\overline{1, K}$ functions are differentiable and convex. $g_{k}(X), i=\overline{1, M}$ is continuous, the set of possible points

$$
S=\left\{X \in R^{N} \mid G(X) \leq 0, X^{\min } \leq X \leq X^{\max }\right\} \text { given with (4)-(5) constraints isn't empty and is compact. }
$$

Formulas (2)-(5) generate a generalized mathematical model of the activity of a technopark. It is required to find such an $X^{0} \in S$ vector of parameters that each component of the $\mathrm{F}(\mathrm{X})$ vector-function could be minimal. Methods based on the normalization of criteria can be used for the solution of this issue. They allow to solve this issue in both equal value criteria and given priority of the criterion cases.

\section{Econometric Model of Innovative Product or Service Production in Technoparks}

Based on this approach, initial indicators have been determined to establish an econometric model for the analysis of innovation and science-intensive products or service production in the activity of technoparks.

$\mathrm{Y}$ is a dependent variable and characterizes Gross Product Launch in Technopark (GPLT-Y) and the volume of services (man).

$\mathrm{X}_{\mathrm{i}}$ independent variables characterize the following indicators in technoparks:

HER- $X_{1}$ - heat and energy resources costs, man., applied to the product -service launch of the technopark (GPLT), MTR- $X_{2}$ - material and technical resource costs, man. of GPLT,

$\mathrm{SCP}-\mathrm{X}_{3}$ - costs for the purchase of semi-finished and complementary products, man.,

FFI- $\mathrm{X}_{4}$ - Fundamental funds and infrastructure elements, man., SAF- $\mathrm{X}_{5}$ - Salary (basic, creative, supplementary) fund, man., INV-X - Investment incentives (all sources), man., SRE- $\mathrm{X}_{7}-$ Scientific research and education costs, man., ECO-X $\mathrm{X}_{8}$ - Environmental protection and ecological balance costs, man., SPD- $\mathrm{X}_{9}$ Social protection and public development costs, man., IRR-X $\mathrm{X}_{10}$ - Innovative research and perspective research costs, man., BTE- $\mathrm{X}_{11}$ - expediency degree of "Resource-production-sales" business environment, assessment of 
the expert group on the $[0,10]$ scale, INV-X $\mathrm{X}_{12}$ - Innovative degree of cycle "Science-education-researchinnovation-production", assessment of the expert group on the $[0,10]$ scale, HEA-X $\mathrm{X}_{13}$ - The ecological and health level of production and environment, assessment of the expert group on the $[0,10]$ scale.

Taking these into account, the econometric model of the technopark is proposed as follows in such way that its relevant parameters are determined by computer software packages based on least-squares method [6]:

$$
Y=a_{0}+\sum_{i=1}^{13} a_{i} X_{i}+E
$$

To evaluate the activity of the technopark, both indicators and goals-criteria hierarchy are established. On the high level, generalized indicators and goal criteria in accordance with the directions of the main activity, and on the lower levels, relatively specific indicators and goals - subcriteria are set $[12,13]$. The information model of the technopark is created using the interaction mechanisms of these indicators and criteria.

The ratio of indicators to each other is analyzed in accordance with the relevant formulas and evaluation tables are compiled. These objectives are ranked according to their power of influence to the main result for evaluating the effectiveness of the activity of technopark. Relevant importance ratios based on the experts assessment are determined for them according to the developed algorithm.

In order to analyze the activity of technopark on indicators and conduct comparative evaluations information on both the upper and lower levels of indicator groups are used. The ratio of the indicators to each other is drawn up in the analysis and evaluation tables in accordance with the relevant formulas. To evaluate the efficiency of the activities of technopark, these goals are ranked according to the power of influence on the main result. Relevant importance ratios are determined for them. This process is carried out by the expert group in the following stages.

In the first stage, the rank of each criterion is determined. The following markings can be used for this.

$\mathrm{i}$ - index of the high level criterion, $(i=\overline{1, n})$;

$\mathrm{j}=$ index of experts in the relevant expert group, $(j=\overline{1, m})$;

$\mathrm{K}_{\mathrm{i}}$ - the result indicator of the $\mathrm{i}$-th criterion, $(i=\overline{1, n})$;

$\mathrm{b}_{\mathrm{ij}}$ - the point given by $\mathrm{j}$-th expert to $\mathrm{i}$-th criterion, $(i=\overline{1, n}),(j=\overline{1, m})$;

$\mathrm{S}_{\mathrm{i}}$ - total points given to i-th criterion by experts, $S_{i}=\sum_{j=1}^{m} b_{i j}(i=\overline{1, n})$;

$\mathrm{r}_{\mathrm{i}}-$ rank of i-th criterion, $r_{i}=\frac{S_{i}}{m},(i=\overline{1, n})$.

In the second stage, the relative importance ratio $-\mathrm{k}_{\mathrm{i}}$ of each criterion $\mathrm{K}_{\mathrm{i}}$ is determined. Here the condition $\sum_{i=1}^{n} k_{i}=1$ must be satisfied.

For the calculation of $\mathrm{k}_{\mathrm{i}}$, firstly, the opposite number $\left(\mathrm{Si}^{*}\right)$ of each $\mathrm{Si}$ is determined:

$S_{i}^{*}=\frac{1}{S_{i}},(i=\overline{1, n})$. Then the obtained $\mathrm{Si}^{*}$ coefficients are normalized, i.e. $k_{i}=\frac{S_{i}^{*}}{\sum_{i=1}^{n} S_{i}^{*}}$. It is obvious that in this 
case the condition $\sum_{i=1}^{n} k_{i}=\sum_{i=1}^{n} \frac{S_{i}^{*}}{\sum_{i=1}^{n} S_{i}^{*}}=1$ will be satisfied.

In the third stage, if needed, the subcriteria of $\mathrm{L}_{\mathrm{i}}$ number in accordance with any $\mathrm{i}$-th criterion are determined. Then, as in the I and II stages, relevant ranks and relative importance ratios for each subcriterion are determined by the group of experts.

$l_{i}=\overline{1, L_{i}}$ index of subcriteria relevant to i-th criterion, $(i=\overline{1, n})$;

$K_{l_{i}}^{i}-$ result indicator of $\mathrm{l}_{\mathrm{i}}$-th subcriterion relevant to $\mathrm{i}$-th criterion, $l_{i}=\overline{1, L_{i}}$;

$k_{l_{i}}^{i}$-relative importance ratio of $\mathrm{l}_{\mathrm{i}}$-th subcriterion relevant to $\mathrm{i}$-th criterion, $l_{i}=\overline{1, L_{i}}$;

$k_{l_{i}}^{i}$ coefficients are also defined within the following conditions as before: $\sum_{l_{i}=1}^{L_{i}} k_{l_{i}}^{i}=1, \quad(i=\overline{1, n})$.

In other words, points are given to each of the subcriteria by the group of experts and the total of these points is calculated. Then, when the relevant ranks are assigned, the numerical inverse of the total points is calculated and the obtained results are normalized.

In the IV stage the realization degree or result indicator of each criterion $\left(K_{i}\right)$ and its relevant subcriteria $\left(K_{l_{i}}^{i}\right)$ is determined. Then integral efficiency criterion of the activity of technopark (IET) which is considered composite index can be defined as a function of these criteria. Thus,

$$
\begin{gathered}
\mathrm{IET}=\mathrm{F}\left(\mathrm{K}_{1}, \mathrm{~K}_{2}, \ldots, \mathrm{K}_{\mathrm{n}}\right), \\
\mathrm{K}_{\mathrm{i}}=\mathrm{F}_{\mathrm{i}}\left(K_{1}^{i}, K_{2}^{i}, \mathrm{~K}, K_{L_{i}}^{i}\right),(i=\overline{1, n})
\end{gathered}
$$

In the particular case, if we assign $\mathrm{F}$ and $\mathrm{F}_{\mathrm{i}}$ functions as a linear function that is defined as the product of the values of relevant criteria and their relative importance ratios, then the result can be defined as follows: IET = $\sum_{i=1}^{n} k_{i} K_{i}$. For i-th criterion in particular the result may be determined as follows: $K_{i}=\sum_{l_{i}=1}^{L_{i}} k_{l_{i}}^{i} K_{l_{i}}^{i},(i=\overline{1, n})$.

\section{The Analysis of Practical Realization Results of the Models Developed for Innovative Product-Service Manufacturing Management In Technoparks}

The system of indices, subindices and indicators for comparative evaluation of the activity of technopark is divided into different hierarchical levels $[14,17]$. 1st national level - composite index of technoparks, 2nd level - 10 indices, 3rd level - 106 subindices, 4th level - 320 indicators of macro/micro character, 4th level indicators include official statistics and other external and internal indicators. 4th level indicators play a basic role in determining mostly 3 rd and 2 nd level subindices by experts. In this case, absolute indicators and their specific values are used. The approach here is different and can be carried out individually according to each particular situation. 
To form composit indexsuggested for comparative evaluation of activity of technoparks, the weight ratios given by experts to selected indexes have been studied accordingly $[14,15]$. Then the final score for each index and technopark is calculated.

Impact (weight) ratios of the indices chosen as a result of expert assessment are evaluated as follows: 1) Significance and scale index (SCA) - $0,05,2$ ) Infrastructure and information provision index (INF) $-0,06,3$ ) Affordable business environment index (BEI) -0,10,4) Index of investment and financial resources and material and technical resources (IMR) -0,13, 5) Innovative potential, activity and environment index (IPA) $0,18,6)$ Human resources and qualified personnel training index (HRP) - 0,08, 7) Index of scientific research, experimental development and innovative projects (SRI) -0,12,8) Index of innovation products and services (IPS) - 0,11,9) Index of effective management and creative outcomes (EMC) -0,09, 10) Index of socialecological development (SED) - 0,08.

Experimental assessments of complex activity of technoparks were conducted on a variety of variants based on expert assessment method and their final ranking ratios were determined (table 1). The highest final price belonged to Sumgait Technologies Park, with 7.42 points on a 10-point system.

Table 1. Final Rating Score of Complex Activity of Some Technoparks of Azerbaijan

\begin{tabular}{|c|c|}
\hline Name of technoparks & Rating \\
\hline Sumgait Technologies Park & 7.42 \\
\hline Sumgait Chemical Industry Park & 6.31 \\
\hline High Technologies Park of MTCHT & 5.61 \\
\hline High Technologies Park of ANAS & 5.42 \\
\hline Technopark of Engineering University & 4.86 \\
\hline Science and Technology Park of ANAS & 4.34 \\
\hline Balakhany Eco-industrial Park & 3.78 \\
\hline Garadagh Industrial Park & 3.36 \\
\hline
\end{tabular}

For the purpose of studying the activity of the technoparks, analysis of potential socio-economic development indicators of the technopark has been carried out. Correlation-regression analysis methods has been used to evaluate the activity of technoparks, to detect the interconnection of some indicators.

As an investigated indicator, total innovative product or service production volume in the technopark has been accepted. Based on the initial indicators of the activity of technoparks, its econometric model was established. For the purpose of identifying important factors, the construction of a pair correlation matrix defining the activity of technopark has been implemented [16, 17].

The results and researches achieved on the basis of carried out calculations show that the built regression models are of high quality. The statistical significance of all models is confirmed by determination, correlation, specified determination coefficients and the Fischer criterion. Analysis of Sudent-T statistics also shows that factors included in regression models are statistically significant and they have a significant impact on the size of the overall product. The final table of regression analysis, additional characteristics of assessment of the impact of factors, prediction of the indicators of the activity of technopark, by using of multi-factor regression analysis it is possible to predict the total innovation product volume [18].

An input matrix has been established based on observed expert assessment of non-dependent variables included in the econometric model. The graph of distribution of observed values of the variables according to the input matrix is given in Figure 3. The regression ratios of the econometric model were calculated using the least squares method on the basis of the matrix values. 


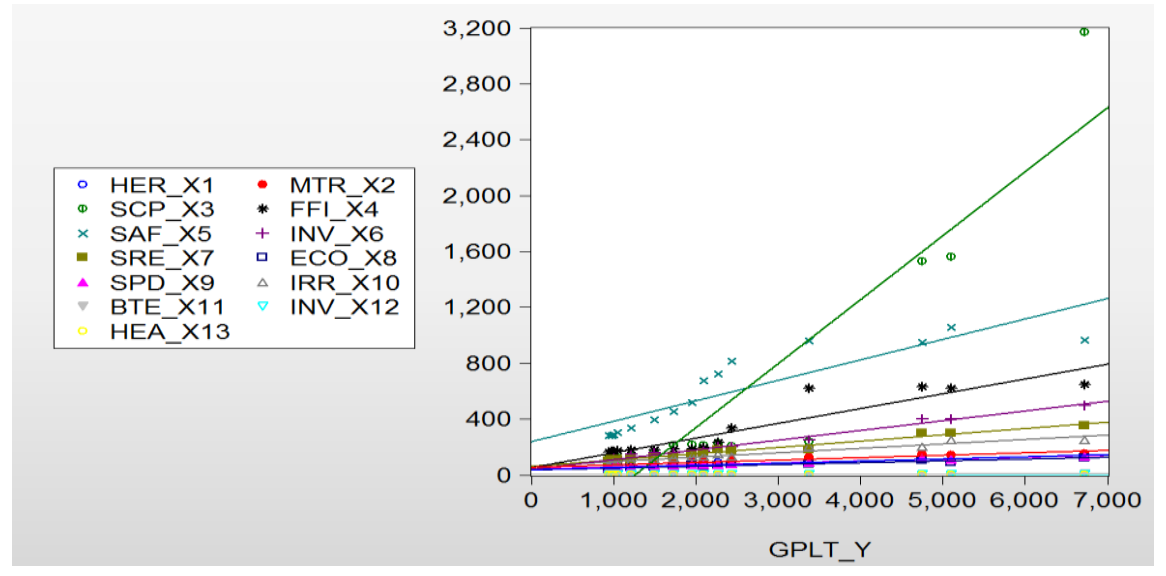

Fig.3. Graph of Distribution of Observed Values of Variables in Technopark

The graphs and calculations shown are carried out using the special software developed on the basis of the synthesis of relevant modules of statistical software packages

The final table of regression analysis, the additional characteristics of the assessment of factors impact, the prediction of the activity indicators of technopark, using the multifactor regression analysis, it is possible to predict the total innovative product or service volume.

Indices, subindices and indicators system for comparative assessment of technoparks are divided into different hierarchical levels [14]. 1st national level - composite index of technoparks, 2nd level - 10 indices, 3rd level - 106 subindices, 4th level - 320 macro / micro character indicators, official statistics and other external and internal indicators for 4 th level indicators have been applied. $4^{\text {th }}$ level indicators play a key role in determining mostly $3^{\text {rd }}$ and $2^{\text {nd }}$ level subindices by experts. In this case, absolute indicators and their specific values are used. The approach here is different and can be carried out individually according to each specific situation. The econometric models of technoparks are established based on the initial indicators of their activity. Initial indicators on multifactor regression models for econometric analysis of innovation and science-based product-service manufacturing in technoparks were proposed. Different statistical analyses were carried out on the basis of observational values of experimental data related to initial data. The analyses have confirmed that the identification of dependence by classifying initial data and technoparks according to three separate groups has more significance.

\section{Conclusion}

Technoparks are considered the main driving force of economic development in the transition to information society and knowledge economy. The application problems of mathematical methods and techniques in the provision of sustainable economic development in innovative product and service manufacturing processes in technoparks in the direction of accelerating of the process of formation of knowledge-based economy and intellectual society, strenghtening of interconnections between science-education-production areas are of the topical issues for the modern era. Composite indices and subindices which form it for the comparative evaluation of the complex activity of technoparks are suggested. Impact (weight) factors of the composite indices selected as a result of expert assessment have been determined. The final score for each index of experts assesment is calculated.

Based on the initial indicators of the activity of technoparks, its econometric model was established. Initial indicators on multi-factor regression model for econometric analysis of innovation and science-intensive 
product manufacturing in the technoparks have been suggested.

Carried out calculations show that the built regression models can be used for practical purposes. The statistical significance of all models is confirmed by the Fischer criterion. Analysis of Sudent-T statistics shows that factors included in regression models are statistically significant and they have a significant impact on the size of the overall product. Practical realization results of the models developed for innovative product manufacturing management in technoparks have been analyzed. The final rating score of complex activity of some technoparks of Azerbaijan has been determined.

In the first group, the dependence of product / service launch activity of production-based technoparks on the five indicators of "production resources" group indicators $\left(\mathrm{HER}-\mathrm{X}_{1}, \mathrm{MTR}-\mathrm{X}_{2}, \mathrm{SCP}-\mathrm{X}_{3}, \mathrm{FFI}-\mathrm{X}_{4}, \mathrm{SAF}-\mathrm{X}_{5}\right)$ was more. In the second group, five development resources indicators (INV- $\mathrm{X}_{6}, \mathrm{SRE}-\mathrm{X}_{7}, \mathrm{ECO}-\mathrm{X}_{8}, \mathrm{SPD}-\mathrm{X}_{9}, \mathrm{IRR}$ $\mathrm{X}_{10}$ ) play an important role in the service-based technoparks. The activity of the third group of scientific and technological innovation parks depends on three institutional environment indicators $\left(\mathrm{BTE}-\mathrm{X}_{11}, \mathrm{INV}-\mathrm{X}_{12}\right.$, HEA- $X_{13}$ ) from the "innovative resources" group. In this group all 3 indicators are assessed on the $[0,10]$ scale by expert group. Therefore, in the subsequent analysis process, directly these indicator groups are taken as a basis. As the statistical significance of established regression models is sufficient, it is useful in practical management work. Analyses have shown that factors included in regression models are statistically significant and have a significant impact on the overall volume of product or service. Additional characteristics of the regression model allow predicting the activity indicators of technoparks, carrying out the calculation of the total innovative product-service volume.

\section{Reference}

[1] Strategic Road Maps for development of national economy and main economic sectors. Azerbaijan, Baku, december 6, 2016. www.president.az

[2] Development Concept "Azerbaijan - 2020: Outlook for the Future". Baku, 2012, www.president.az

[3] Azerbaijani President's decree on the approval of the National Strategy for Information Society Development in the 2014-2020 period. Baku, 2014, www.president.az

[4] "Law of Science of the Republic of Azerbaijan". Baku, 2016. www.science.gov.az

[5] Kleiner G.B. Economy. Modeling. Mathematics. Selected works. CEMI RAS, 2016. - 856 p.

[6] Musayev A.F., Gahramanov A. Introduction to Econometrics. Textbook. Baku, 2011. 176 p.

[7] Kameneva S.A., Boriskina I.P. Matematical models in economy. Bulletin of the VU. Вестник Волжского Университета. 2016, №2, vol 2, p.25-29.

[8] Belenky V.Z., Trofimova N.A. Analysis and modeling of economic processes / The Collection of Articles, ed. Issue 10. - Moscow: CEMI RAS, 2013. - 155 p.

[9] Shahverdiyeva R.O. Information and software development issues of scientific and technological innovation technoparks. Actual scientific-practical problems of software engineering. I Republic Conference. Baku, 2017, p.311-314.

[10] Aliyev A.G., Shahverdiyeva R.O. Economic and mathematical modeling of innovative structures in conditions of uncertainty. Institute Mathematics and Mechanics of ANAS. International conference on actual problems of mathematics and mechanics. Baku, 2014, p. 26-28.

[11] Barinova V.A., Maltceva A.A., Sorokina A.V., Eremkin V.A. Approaches to assessing the adequacy and efficiency of the innovation infrastructure facilities in Russia. Innovations, 2014, №3(185), pp. 4251.

[12] Aliyev A.G., Shahverdiyeva R.O. About the development of the algorithm to evaluate the efficiency of ict techno parks. IV International Conference "Problems of Cybernetics and Informatics" (PCI'2012) September 12-14, 2012, pp.206-209.

[13] Neeru Garg, Munish Kumar. Clustering of multi scripts isolated characters using k-means algorithm. International Journal of Mathematical Sciences and Computing. 2015, pp.22-29.

[14] Aliyev A.G., Shahverdiyeva R.O. Scientific-methodological bases of development of the composite 
indicators system of comparative evaluation of technoparks' activity. Problems of Information Society. 2017, p. 61-74.

[15] Bhattacharya B., Saha B. Analysis of signalling time of community model. International Journal of Mathematical Sciences and Computing. 2015, pp.8-21.

[16] Gusarova O.M., Kuzmenkova V.D. Modeling and analysis of the trends of development of regional economy. Fundamental Research, 2016, №3, p.354-359.

[17] Shahverdiyeva R.O. Development of an econometric model of innovative products or services in technology parks. International scientific-practical conference on "Strategic economic reforms". Institute Economy of ANAS. Baku, 2017, p. 587- 594.

[18] Yazan A.M., Ali M. M., Alaa S.F. Data- and workflow customer-oriented software process models. International Journal of Mathematical Sciences and Computing, 2015, pp.21-33.

\section{Authors' Profiles}

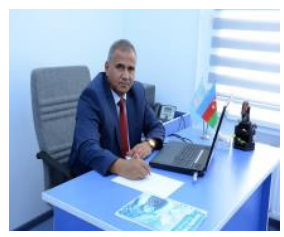

Ph.D. in economics, ass. professor Alovsat Aliyev (born January 8, 1956). Head of department of the Institute of Information Technology of ANAS, Baku, Azerbaijan. He has a total number of 150 scientific articles and 5 books. Alovsat Aliyev continues to conduct scientific-research works and deals with issues such as characteristics of ICT application in economical processes and management authorities, information problems in social-economical systems, scientific-theoretical basics of formation of information society, information economy, determination of demonstrative systems in ICT field, research of reasons of establishment of digital differences in the society, study economical basics, problems of informatization of humanitarian fields, humanitarian aspects of ICT.

Areas of interest: innovative information and knowledge economy, technoparks, green economy, computers and information science, econometrics.

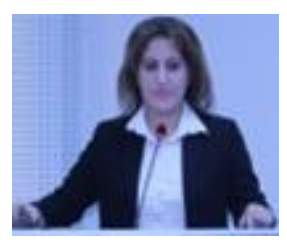

Senior scientist of Institute of Information Technology of ANAS, Baku, Azerbaijan. She has a total number of 38 scientific articles. Her articles dedicated to actual ICT problems, innovation economy, technoparks, are regularly published in various scientific journals and newspapers.

Areas of interest: information systems, process of innovation, technoparks, management.

How to cite this paper: Alovsat Garaja Aliyev, Roza Ordukhan Shahverdiyeva,"Application of Mathematical Methods and Models in Product - Service Manufacturing Processes in Scientific Innovative Technoparks", International Journal of Mathematical Sciences and Computing(IJMSC), Vol.4, No.3, pp.1-12, 2018.DOI: 10.5815/ijmsc.2018.03.01 